\title{
RESENHA DE O ITINERÁRIO DE BENJAMIN DE TUDELA
}

\section{REVIEW OF THE ITINERARY OF BENJAMIN OF TUDELA}

Júlia Wasserman*

\begin{abstract}
Resumo: Em meados do século XII, Benjamin de Tudela deixou a Península Ibérica para empreender, durante um espaço de catorze anos, uma viagem através da Europa, da África e da Ásia. Tudo o que se sabe a respeito de sua jornada foi documentado por ele próprio, em hebraico, em seu livro de viagens intitulado posteriormente como $O$ itinerário de Benjamin de Tudela. Os seus registros, significativos enquanto documento histórico e geográfico de boa parte da terra conhecida até então, destacam-se não apenas por refletir a mentalidade do medievo, como também por oferecer a mais completa descrição da comunidade judaica existente naquela época.
\end{abstract}

Palavras-chave: Benjamin de Tudela. Literatura judaica. Literatura de viagem. Medievo.

\begin{abstract}
In the middle of the 12th century, Benjamin of Tudela left the Iberian Peninsula to undertake, over fourteen years, a trip through Europe, Africa and Asia. All we know about his journey was documented by himself, in hebrew, on his travel book later entitled as The itinerary of Benjamin of Tudela. His records, meaningful as a historic and geographic document of the known land until then, stand out not only for reflecting the medieval mentality, but also for offering the most complete description of the jewish community at that time.
\end{abstract}

Keywords: Benjamin of Tudela. Jewish literature. Travel literature. Medieval.

Paulo Lopes, ao discorrer sobre as peculiaridades dos livros de viagens medievais, diz que o conjunto de relatos de peregrinação de que temos conhecimento forma um gênero literário composto por múltiplas faces ${ }^{1}$. São características comuns que fazem com que cada uma dessas composições, peculiares em si mesmas, sejam passíveis de se unirem em um grupo mais ou menos etiquetado. Mas parece incontestável que, dentre os traços compartilhados por cada uma delas, o mais significativo se encontre na sua necessidade de "dar a conhecer o mundo"². E não

\footnotetext{
* Graduanda em Letras Português-Hebraico pela Universidade de São Paulo. Supervisão: Prof. Moacir Amâncio.

Email:<juliawasserman@usp.br>.

${ }^{1}$ LOPES, Paulo. Os livros de viagem medievais. In. Revista Medievalista, ano 2, n. 2, Lisboa, 2006. Disponível em <https://dialnet.unirioja.es/descarga/articulo/4060212.pdf>. p. 1.

2 Ibid., p. 11.
} 
somente porque essa questão também era, aos redatores das viagens, uma forma de transmitir os mais variados conhecimentos aos seus contemporâneos. Mas sobretudo porque, para a posteridade, cada um dos registros, verossímil ou fictício em qualquer medida, é uma documentação que dá luz à mentalidade do homem medieval; um arquivo que nos permite entrever o mundo da Idade Média através dos olhos daqueles que nela existiram.

O relato da viagem percorrida pelo rabi Benjamin ben Ioná de Tudela é um dentre vários relatos que podemos contemplar para ter acesso às lentes que filtraram a visão do medievo. Ocorrido num intervalo de catorze anos, algo entre 1159 e 1173, é relatado num hebraico rabínico através de páginas que carregam um alto teor histórico e geográfico, uma vez que descrevem grande parte da terra conhecida no século $\mathrm{XII}^{3}$, bem como os povos que por ela se espalhavam, quais eram os seus costumes e com que tipos de atividade comercial e religiosa se ocupavam. Mas, mais do que por isso, os relatos de Benjamin ganham destaque especial, no interior da literatura de viagem medieval, também pelo seu valor sociológico e etnográfico. De acordo com uma análise de Salo W. Baron, O itinerário de Benjamin de Tudela compõe, ao lado dos relatos de Petahia bar Iaakov, o ponto mais alto da literatura de viagem medieval judaica ${ }^{4}$. E isso não é por acaso, afinal, boa parte de seu escrito foi dedicada ao registro das comunidades judaicas com as quais se deparou em sua jornada intercontinental.

Foi numa conjunção de fato e fantasia que Benjamin encontrou os meios de apreender as realidades conhecidas e desconhecidas. Escreveu sobre tudo o que encontrou, estendendo-se naquilo que deve ter lhe parecido mais interessante ou significativo. Há pesquisas que buscam apurar o quanto de veracidade há em seus relatos, e embora esse processo científico seja importante para uma maior compreensão histórica do período medieval, não podemos tomá-lo, a todo momento, como determinante ao analisar o livro sob um ponto de vista cultural e literário. Verdadeiras ou não, as palavras de Benjamin expressam uma visão de mundo. Devemos lembrar e considerar que a noção de realidade é muito marcada por ideologias que se transformam no decorrer do tempo. O que hoje nos parece mito, pode ter sido a verdade para aqueles que viveram no passado. Mary Anne Junqueira, ao tratar da literatura de viagem de Jean de Mandeville, reforça que a sua importância está na "verdade que ele quis construir e não

\footnotetext{
${ }^{3}$ ASHER, A. A introdução de Asher. In. GUINSBURG, J. (Org. e trad.). O Itinerário de Benjamin de Tudela. $1^{\mathrm{a}}$ ed. São Paulo: Perspectiva, 2019. Edição Kindle, posição 176-208.

${ }^{4}$ BARON, S. W. Aos olhos do século XX. In. GUINSBURG, J. (Org. e trad.). O itinerário de Benjamin de Tudela. $1^{\mathrm{a}}$ ed. São Paulo: Perspectiva, 2019. Edição Kindle, posição 285. (Recorte que J. Guinsburg faz da análise de Salo W. Baron sobre a importância do Itinerário de Benjamin de Tudela, que está presente em A social and Religious History of the jews, v. VI, p. 222-224, Columbia University Press).
} 
na veracidade do relato" ${ }^{5}$. Suas palavras continuam a fazer muito sentido se as colocarmos sobre a verossimilhança do que Benjamin de Tudela registrou.

A. Asher comenta que os conteúdos da obra de Benjamin podem ser divididos entre $o$ que ele viu e o que ouviu 6 . Se observarmos isso com base na atual visão do que se configura como realidade, tendemos a pensar imediatamente que as coisas vistas por ele seriam mais passíveis de veracidade do que aquelas que foram ouvidas. Mas Benjamin não parece ter pensado assim: ele registrava as crenças sem contestá-las, e as suas palavras chegam até nós com um ar de curiosidade que parece repleto de confiança e maravilhamento para com o desconhecido. Benjamin tinha a intenção de conhecer o mundo, observava diferenças e semelhanças e assimilava tais informações do modo que sabia fazer. E esse modo é filtrado não só pelo espírito da descoberta, como também pela imaginação.

É por isso que, embora Asher afirme que O Itinerário de Benjamin de Tudela contém "mais fatos e menos fábulas do que qualquer outra produção contemporânea" ${ }^{7}$, não podemos deixar de observar o elemento fantástico que existe na obra. Esse aspecto parece estar ao lado do documental não como um elemento de contraste, mas como constituinte de um todo que tinha o seu próprio funcionamento; como parte da verdade em que Benjamin confiava e, portanto, ocupou-se em relatar. Para a sua visão, não é muito relevante o quanto a posteridade acha que os testemunhos que ele acolheu tratam-se de lendas ou de histórias populares.

Quando fala sobre o caminho até a China, por exemplo, cita as intensas correntes marítimas que impeliam navios ao mar de Nipka ${ }^{8}$. Lá, marinheiros ficavam presos, estáticos em meio à água, e o elemento fantástico dessa narrativa se manifesta quando Benjamin conta sobre o grifo, um grande pássaro que vigiava os navegadores e os capturava, crendo que fossem animais, para levá-los ao alto de uma montanha. Nesse lugar, os marinheiros, disfarçados com couro animal, matavam a ave e pela montanha caminhavam para enfim escapar da situação em que tinham sido colocados. Era o modo que tinham, naquele contexto, de fugir daquele tipo de emboscada. $^{9}$

\footnotetext{
${ }^{5}$ JUNQUEIRA, p. 53 apud FRANÇA, 2007 apud FIGUEIREDO, D. W. V. Relatos de Viagem no Medievo: a questão da alteridade n'O itinerário de Benjamin de Tudela. Tese (Bacharelado). Centro de Filosofia e Ciências Humanas da Universidade Federal de Santa Catarina. Florianópolis, 2019. p. 17.

${ }^{6}$ ASHER, op. cit., posição 208.

${ }^{7}$ Ibid., posição 176 .

${ }^{8}$ Em nota de sua tradução, J. Guinsburg comenta que Benjamin de Tudela foi o primeiro Europeu a pelo menos mencionar a China e que, em relatos de autores árabes da Idade Média, há pouca informação sobre o país. "Em nenhum de seus registros é nomeado o mar de Nipka, e não é improvável que Benjamin tenha cunhado esse nome, ele próprio, a partir de uma raiz hebraica que ocorre na Bíblia quatro vezes." (GUINSBURG, 2019, posição 1695.) ${ }^{9}$ TUDELA, 2019, posição 1239.
} 
Hoje isso soa como uma narrativa completamente maravilhosa, algo que encontraríamos em algum livro ou filme de ficção fantástica. Benjamin, contudo, inseriu tal elemento no interior de seu relato, a despeito de todo o seu teor que nos é imaginativo, porque parecia confiar nele; cria ser algo que de fato acontecia nos meandros de tais viagens marítimas e que por isso mesmo devia ser registrado. Além disso, de acordo com Jacob Guinsburg, a imagem dessa grande ave que espreitava o mar está contida numa antiga e difundida fábula, tanto é que também aparece nos relatos de viagem de Marco Polo, assim como em alguma parte de Mil e uma noites. ${ }^{10}$ Isso nos dá ainda mais confirmações de que, aos olhos medievais, fato e ficção tinham uma dinâmica compartilhada. Tal era a realidade do medievo e, na análise da obra, ela importa mais do que a sua comprovação factual.

Mas é claro que aquilo dito por Asher — sobre a relevância histórico-geográfica de os relatos de Benjamin conterem mais fatos do que fábulas ${ }^{7}$ - é tão importante quanto tomarmos a fantasia enquanto elemento que estrutura a mentalidade medieval. Como foi dito anteriormente, Benjamin coloca-se a conhecer o mundo no desdobramento de sua viagem. Nesse conhecer, desvenda não somente as diferenças, mas também as similaridades: conhece os judeus.

É bastante explícito que Benjamin era judeu, e o próprio Asher diz que isso é tão evidente que não requer qualquer prova ${ }^{11}$. Mesmo se não tivéssemos acesso às informações da Introdução Hebraica aos seus escritos, que o descreve como o "rabi Benjamin (...) um homem sábio e inteligente, versado na Lei e na Halakhá"12 continuaríamos sendo capazes de deduzir esse fato pelo conteúdo da obra. E não porque Benjamin tenha dito isso claramente - na verdade, ele nunca revelou detalhe algum de si mesmo - , e sim porque ao longo de todo o seu livro de viagens vemos que, tanto quanto citar e descrever as cidades pelas quais passou, Benjamin preocupou-se em relatar objetivamente os judeus com que se deparou.

Fez isso por meio de notações de dados numéricos da população, bem como pela recorrente nomeação dos sábios de cada uma das comunidades judaicas encontradas. Vez ou outra, além de listar nomes cuidadosamente, Benjamin citou as atividades econômicas e às vezes políticas com as quais os seus correligionários se ocupavam, sua situação e estruturação nas sociedades (sobretudo aqueles judeus que viviam longe da concentração da vida judaica), assim como também fez questão de enfatizar o amplo conhecimento religioso que alguns deles

\footnotetext{
${ }^{10}$ GUINSBURG, op. cit., posição 1698.

${ }^{11}$ Ibid. posição 192.

${ }^{12}$ Introdução Hebraica. In. GUINSBURG, J. (Org. e trad.). O Itinerário de Benjamin de Tudela. $1^{\text {a }}$ ed. São Paulo: Perspectiva, 2019. Edição Kindle, posição 347.
} 
possuíam. Segundo Asher, “a narrativa de rabi Benjamin contém a mais completa descrição existente do estado e do número de judeus no século XII"13.

E ele teve a atenção de mencionar esses judeus, de fixá-los na memória escrita, tanto quando eram muitos - como em Bagdá, onde diz que, naquela altura, havia cerca de quarenta mil judeus ${ }^{14}$ - , como quando eram poucos e até somente um - como no seu registro do começo da terra de Israel, em que comenta de "São Jorge, que é Lud, onde vive um judeu, que é tintureiro" 15 . Mesmo se não houvesse judeus em determinada localidade, era exatamente a sua ausência que Benjamin anotava. Asher diz que muitos teólogos viram, nisso, algo de hiperbólico, uma tentativa de Benjamin de engrandecer a real demografia judaica ${ }^{16}$. De todo modo, não temos como ignorar a importância de tal demarcação, sobretudo porque os dados numéricos, em boa parte dos casos, vêm sempre acompanhados dos nomes dos sábios que estavam à frente das comunidades judaicas — "à sua testa", como diz Benjamin tantas vezes — e também de constantes menções ao seu conhecimento e erudição. Sempre que algum desses sábios tinha um papel importante na sociedade, Benjamin o referia com mais detalhes - é o que faz, por exemplo, na descrição da comunidade judaica de Constantinopla, quando cita o rabino Salomão Hamitsri, único judeu com permissão de montar a cavalo, já que era médico do $\mathrm{rei}^{17}$.

É também bastante notável que, tendo percorrido caminhos tão extensos, deparando-se com judeus que de dispersavam por locais tão remotos e distantes dos grandes centros judaicos, Benjamin não deixou de encontrar acolhimento e identificação em qualquer que fosse a comunidade judaica avistada. Em seu relato da França, diz que os eruditos judeus que ali viviam "são caridosos e hospitaleiros para com todos os viajantes, e são como irmãos e amigos a todos os seus irmãos, os judeus"18.

Diego Wieser Vieira de Figueiredo fala um pouco sobre isso em seu artigo a respeito da questão da alteridade nos relatos de Benjamin de Tudela. Segundo a sua análise com base na alteridade, Benjamin via os judeus como $E u$, identificados e assimilados à sua própria identidade judaica, e não como o Outro, mesmo que fossem judeus espalhados por quilômetros distantes no mundo. ${ }^{19}$ A isso se soma outra reflexão de Figueiredo, no mesmo artigo, em que aponta um dos aspectos utilitários que pode ser atribuído à composição do livro por Benjamin.

\footnotetext{
13 ASHER, op. cit., posição 240.

14 TUDELA, 2019, posição 914.

15 Ibid. posição 653.

16 ASHER. op. cit., posição 224.

17 TUDELA, 2019, posição 583.

18 Ibid., posição 1404 .

${ }^{19}$ FIGUEIREDO, op. cit., p. 31-44.
} 
Considerando que desde a Primeira Cruzada os judeus estavam sujeitos a perseguições religiosas, ele aponta que as informações fornecidas por Benjamin, tanto das cidades pelas quais passou, quanto dos nomes dos rabinos das comunidades que encontrou, seriam de grande utilidade aos seus correligionários que pretendiam realizar uma viagem como a sua, uma vez que ele também mapeava as pegadas judaicas através da Europa, Ásia e África. Figueiredo fala, ainda, sobre a hipótese de Benjamin ter traçado uma rota litorânea em sua jornada devido a esse mesmo contexto de perseguição aos judeus na Europa continental, já que seria uma alternativa mais pacífica e segura, muito benéfica se compartilhada com outros judeus. ${ }^{20}$

Mas não foi apenas os judeus que Benjamin preocupou-se em relatar. No seu itinerário, chocou-se contra povos com os quais não estava habituado, aqueles que Figueiredo, ainda com base na lógica da alteridade, diz que Benjamin via como o Outro, pessoas com uma existência oposta à sua ${ }^{21}$. Um exemplo bastante notável está no momento em que descreve os kofar-alTurak. Benjamin diz que eles "não têm narizes e, em seu lugar, têm dois pequenos orifícios, através dos quais respiram" 22 . Tal afirmação não pretendia de modo algum exibir um tipo de percepção preconceituosa. Na verdade, revela com riqueza o estranhamento que Benjamin sente ao se deparar com o desconhecido, com o nunca visto, com aquilo que é tão diferente de tudo o que já viu.

Ao tratar dos drusos, por outro lado, Benjamin utiliza-se de termos que de certo modo os inferiorizam: diz que são "pagãos de um caráter despido de lei" e que "estão imersos em vício, irmãos casando-se com irmãs e pais com suas filhas. ${ }^{״ 23}$ Léon Poliakov, em De Maomé aos marranos, ao tratar do zoroastrismo na Babilônia, diz que cultos incestuosos, tais como esse descrito na tradição dos drusos, eram perturbadores ao entendimento judaico-cristão. ${ }^{24}$ Embora tal situação se dê em outro contexto, ela ajuda a explicar a visão que Benjamin, detentor da mentalidade judaica, teve perante àquele povo e às suas crenças - era o novo, o desconhecido, o estranho.

Já em relação aos cristãos, Figueiredo diz acreditar que Benjamin não se demorou em detalhes sobre eles pois, embora não fossem seus semelhantes (como os judeus eram), faziam parte de uma cultura que compreendia o universo latino ocidental de que ele derivava e que, por consequência, influenciou a formação de seu pensamento. ${ }^{25}$ Ao também tratar dos dois

\footnotetext{
${ }^{20}$ Ibid., p. 25-26.

${ }^{21}$ Ibid., p. 33.

22 TUDELA, 2019, posição 1137.

${ }^{23}$ Ibid., posição 623.

${ }^{24}$ POLIAKOV, L. De Maomé aos marranos. São Paulo: Perspectiva, 1984. Tradução de Ana M. Goldberger Coelho e J. Guinsburg. p. 5-6.

${ }^{25}$ FIGUEIREDO, op. cit., p. 34.
} 
ocorridos aqui citados, sobre os drusos e os kofar-al-Turak, Figueiredo diz que "é no Oriente que Benjamin encontra um mundo que lhe é desconhecido — ou, no mínimo, menos familiar"26.

Se observarmos $O$ itinerário de Benjamin de Tudela em sua completude, podemos levantar hipóteses dos motivos que o levaram a realizar a sua jornada. Pesquisadores já fizeram isso, e como podemos ver nas introduções que A. Asher e Marcus Adler ${ }^{27}$ fizeram às suas traduções da obra, tais hipóteses, assim como pesquisas na mesma área, caminham para um consenso de uma dupla motivação: religiosa e comercial.

Asher, ao explicar o que ele chama de duplo objeto das viagens de Benjamin, começa por dizer que temos de admitir que Benjamin deve ter sido um mercador, uma vez que somente um mercador teria tido o interesse em anotar precisamente a situação de negócios, produção e mercadoria nas cidades e regiões visitadas. As especificações comerciais estão entre os dados mais recorrentes que Benjamin se pôs a documentar. Para completar o seu raciocínio, Asher diz que, "como muitos outros peregrinos maometanos e cristãos da Idade Média, rabi Benjamin visitou Jerusalém, a cidade, e Bagdá, o assento dos últimos príncipes de sua nação" ${ }^{28}$. Sob esse ponto de vista, Benjamin seguiu um itinerário que o levou por caminhos comuns nas viagens medievais que, como afirma Paulo Lopes, costumavam ser feitas em busca de locais sagrados com santuários e relíquias. ${ }^{29}$

Os dois pressupostos para a finalidade da jornada empreendida por Benjamin de Tudela parecem, de fato, muito admissíveis, até porque são os dois para os quais os pesquisadores mais encontraram sentido e explicações em seus empenhados estudos. Contudo, Adler, ao tratar, tal como Asher, dessa dupla motivação religiosa e comercial, faz referência a uma terceira e possível motivação que, no entanto, descarta por falta de indícios palpáveis. Ele se refere à possibilidade de Benjamin ter viajado a fim de "verificar onde os seus expatriados irmãos poderiam encontrar um asilo" ${ }^{\text {30. }}$.

Ele começa o seu raciocínio por falar sobre como os judeus na Idade Média tinham aptidão não só para o comércio como também para a viagem. Diz que não havia uma cidade importante na qual não vivesse um judeu, e que todos, onde quer que fossem, com auxílio do idioma sagrado que compartilhavam, eram recebidos de forma hospitaleira e acolhedora. Em suas palavras, viajar era, para os judeus, "relativamente fácil e o laço do interesse comum

\footnotetext{
${ }^{26}$ Ibid., p. 47.

${ }^{27}$ ADLER, M. N. Introdução de Adler. In. GUINSBURG, J. (Org. e Trad.). O itinerário de Benjamin de Tudela. $1^{a}$ ed. São Paulo: Perspectiva, 2019. Edição Kindle, posição 31-166.

${ }^{28}$ ASHER, op. cit., posição 192.

${ }^{29}$ LOPES, op. cit., p. 4.

${ }^{30}$ ADLER, op. cit. posição 119.
} 
sempre supria um motivo" "31. O ponto alto de sua ideia está no pensamento de que, no tempo das Cruzadas e do sofrimento compartilhado pela comunidade judaica, deve ter se fortalecido em muito o desejo de intercomunicação entre os judeus ${ }^{32}$. Comenta, ainda:

As mais prósperas comunidades na Alemanha, e as congregações judaicas situadas ao longo da rota para a Palestina, haviam sido exterminadas ou dispersadas, e até na Espanha, onde os judeus haviam gozado de completa segurança durante séculos, eles foram impiedosamente perseguidos no reinado mouro de Córdoba. (ADLER, 2019)

Esses são os pontos que ele apresenta para tentar, de algum modo, introduzir a sua suposição, porém, como já foi dito, ele logo a desconsidera por motivos práticos. Contudo, não podemos deixar de notar o quão plausível é essa acepção. Se considerarmos não só o desejo de intercomunicação que ele afirma que existia entre os judeus, mas também o fato de que a consciência de volta à Sion faz parte da vida judaica, essa probabilidade também tem a sua verossimilhança, mesmo que não explícita.

Embora Benjamin não tenha deixado clara uma motivação como essa, podemos ver, por exemplo, no relato de sua passagem por Bagdá, não somente a descrição da beleza e da riqueza de um lugar que era um dos destinos das peregrinações religiosas, como também toda a delineação de um ambiente aprazível para a comunidade judaica. Ele cita que o grande califa Al Abasi era bondoso com Israel, tanto que muitos de seus acompanhantes provinham de lá e ele próprio era versado na Lei e lia e escrevia em hebraico. Diz que ele é "confiante e confiável, sua fala é de paz para todos os homens" e que "é um homem justo e todas as suas ações são para o bem" ${ }^{33}$. Além disso, ao falar especificamente sobre a comunidade judaica da região, indica uma alta quantidade de quarenta mil judeus que "vivem em segurança, prosperidade e honra sob o grande califa" 33 .

O relato de Bagdá é um dos mais compridos de todo o relato de Benjamin, e é provável que os estudiosos associem a motivação religiosa a esse e outros momentos do livro. Podemos pensar que o desejo por um abrigo à comunidade judaica era também algo inconsciente, um sentimento não verbalizado, mas que pode ser lido nas entrelinhas da preocupação que teve Benjamin de desenhar a existência dos judeus no decorrer de sua viagem. De certo é necessário

\footnotetext{
${ }^{31}$ Ibid., posição 112.

32 Ibid., posição 119.

${ }^{33}$ TUDELA, 2019, posição 914.
} 
que pesquisas mais acuradas sejam feitas tendo como enfoque essa questão em específico, que não deixa de ter o seu sentido e por isso deve ser considerada.

Os últimos trechos d'O itinerário de Benjamin de Tudela carregam o sentimento do desejo judaico pela reunião na terra de Israel. É uma consciência mais tribal do que nacional, até porque o conceito de nação é algo muito mais recente. Ainda assim, não temos como ignorar as palavras de Benjamin que, por coincidência ou não, dão desfecho aos seus relatos e, como bem percebeu Figueiredo, dão a impressão de que Benjamin, depois de sua viagem, sentiu-se conectado com a sua comunidade como nunca antes, como se quisesse compartilhar isso e alguma esperança com quem quer que fosse ler as suas palavras ${ }^{34}$.

Israel toda está dispersa em cada país, e aquele que não promove a reunião de Israel não encontrará felicidade nem viverá com Israel. (...) Possa Deus, abençoado seja, ter mercê de nós e deles! (TUDELA, 2019, posição 1404.)

\section{Referências Bibliográficas}

GUINSBURG, J. O itinerário de Benjamin de Tudela. São Paulo: Perspectiva, 2019. Tradução e notas de J. Guinsburg. Edição Kindle.

ASHER, A. A introdução de Asher. In. GUINSBURG, J. (Org. e trad.). O Itinerário de Benjamin de Tudela. $1^{\mathrm{a}}$ ed. São Paulo: Perspectiva, 2019. Edição Kindle, posição 171-265. ADLER, M. N. Introdução de Adler. In. GUINSBURG, J. (Org. e Trad.). O itinerário de Benjamin de Tudela. $1^{\text {a }}$ ed. São Paulo: Perspectiva, 2019. Edição Kindle, posição 31-166. LOPES, Paulo. Os livros de viagem medievais. In. Revista Medievalista, ano 2, n. 2, Lisboa, 2006. Disponível em <https://dialnet.unirioja.es/descarga/articulo/4060212.pdf>.

FIGUEIREDO, D. W. V. Relatos de Viagem no Medievo: a questão da alteridade n'O itinerário de Benjamin de Tudela. Tese (Bacharelado). Centro de Filosofia e Ciências Humanas da Universidade Federal de Santa Catarina. Florianópolis, 2019.

POLIAKOV, L. De Maomé aos marranos. São Paulo: Perspectiva, 1984. Tradução de Ana M. Goldberger Coelho e J. Guinsburg. p. 5 - 6.

\footnotetext{
${ }^{34}$ FIGUEIREDO, op. cit., p. 48.
} 